\title{
Insular Biobjective Routing with Environmental Considerations for a Solid Waste Collection System in Southern Chile
}

\author{
Daniela S. Arango González, ${ }^{1}$ Elias Olivares-Benitez, ${ }^{2}$ and Pablo A. Miranda ${ }^{3}$ \\ ${ }^{1}$ Universidad Popular Autónoma del Estado de Puebla, 21 sur 1103 Barrio de Santiago, 72410 Puebla, PUE, Mexico \\ ${ }^{2}$ Universidad Panamericana, Prolongación Calzada Circunvalación Poniente 49, 45010 Zapopan, JAL, Mexico \\ ${ }^{3}$ Pontificia Universidad Católica de Valparaíso, Av. Brasil No. 2950, Casilla 4059, Valparaíso, Chile
}

Correspondence should be addressed to Elias Olivares-Benitez; eolivaresb@up.edu.mx

Received 6 March 2017; Accepted 22 June 2017; Published 10 August 2017

Academic Editor: Juan C. Leyva

Copyright (C) 2017 Daniela S. Arango González et al. This is an open access article distributed under the Creative Commons Attribution License, which permits unrestricted use, distribution, and reproduction in any medium, provided the original work is properly cited.

\begin{abstract}
This paper presents a biobjective problem for a solid waste collection system in a set of islands in southern Chile. The first objective minimizes transportation cost and the second one reduces the environmental impact caused by the accumulation of solid waste at the collection points. To solve this problem, biobjective mixed integer linear programming is used. In the model, an itinerary scheme is considered for the visit to the islands. The model decides which collection points are visited per island, the collection pattern, and quantity of solid waste to be collected at each site. The quantity of solid waste is obtained dividing the solid waste generated in the island by the number of collection points selected in that same island and the frequency of visits. For this problem, we considered that the environmental impact function varies through the days during which solid waste is accumulated at each collection point. We present an instance based on real data for a set of islands in Chiloe and Palena regions in southern Chile, in which the deposit node is Dalcahue. We used the epsilon-constraint method and the weighted sum method to obtain the Pareto front, using commercial optimization software.
\end{abstract}

\section{Introduction}

There are several causes for the increase of solid waste generation, in the first place population growth coupled with an anthropocentric worldview that justifies the exploitation of the natural resources $[1,2]$ and the economic model that guides the society and the consumption patterns [3]. According to Irigoyen [4], traditional economy considers the economic system as a closed cycle, where there are no considerable external effects, ignoring the impact that societies have on the environment. All this production and consumption culture represents consequences that most of the times are not taken into account because it is complicated to assign a monetary value to the impact they cause [5]. The solid waste management is an issue that involves not only environmental aspects but also many other different factors that coexist in a complex system. The sociocultural, political, technological, environmental, and economical elements are key components of the solution and many times they present contradictory nuances that do not permit easy solutions.

Chile, as most of the Latin American countries, faces growth and development challenges. To improve competitiveness while maintaining life quality of inhabitants, natural resources management and environment preservation should be key factors in public policies [3]. One of the biggest tasks in resource management is solid waste management, and to reach a coherent solution it is mandatory to achieve a systemic combination of all its components, because these cross all the development spheres [3]. MacDonald [6] states that there is a hierarchy of solid waste management strategies which are briefly explained as follows. The first and most important strategy includes preservation and solid waste generation reduction; this implicates rethinking of the processes from a more efficient perspective. It also includes cultural changes, such as environmental education to the consumers and the development and implementation of 
consumption policies that guide society to a more sustainable behavior. Incorporated to this strategy lies the reuse practice. The second strategy considers the importance of recycling and composting, tendency that has been growing since the late $60 \mathrm{~s}$, especially in developed countries. The third strategy looks for the incineration and energy recover. Efficient incineration technologies have been developed and the solid waste energy potential is enormous; nevertheless, it requires high investment and Latin American countries have not implemented it [6]. The least desired strategy is solid waste disposal at controlled landfills. Unfortunately, in Latin American countries, this is the most frequent situation [7] and most of the times it happens in uncontrolled dump sites, causing not only environmental degradation but also health problems to the surrounding population.

The institutions in charge of solid waste management face a tremendous amount of information and resources that need to be organized and taken into consideration. In many occasions, these institutions do not have the tools or techniques for adequate decision-making. Because of the nature of this problem, it is very complicated to find mathematical models that include all the components of a solid waste management system [8,9]; however, in the operation research field, some efforts have been done $[10,11]$. The existent solid waste management models are classified into fourteen categories [12]: waste generation prediction (WG), facility site selection (FS), facility capacity expansion (FC), facility operation (FO), vehicle routing (VRP), manpower assignment (MA), overall system operation (OS), system scheduling (Sch), waste flow (Flow), environmental performance (EP), technology selection (TS), Cost-Benefit Analysis (CBA) models, Life Cycle Analysis (LCA) models, and multicriteria analysis (MCA) models.

One of the key factors of solid waste management is the solid waste collection systems, because most of the times this waste needs to be transported to sites that are equipped with the appropriate technology. According to Miranda et al. [13], various models for the design of these systems (Waste Collection System Design (WCSD)) have been developed [14-17]. These models are based on the classic vehicular routing problem (VRP) $[18,19]$ with some special considerations: G-VRP (Green Vehicle Routing Problem), PRP (Pollution Routing Problem), EVRP (Emissions Vehicle Routing Problem), and RS-TDE (Routing and Scheduling in TimeDependent Environment), where they look for reduction of polluting emissions to the environment, especially carbon dioxide, as a consequence of the minimization of the total distance, fuel consumption, operative costs, or the selection of uncongested routes [20-34]. Another model is the Routing of Hazardous Materials (RHM) that minimizes the risk to the population and environment caused by hazardous material transportation [35-38]. Other models that have been created are the Waste Collection Vehicle Routing Problem (WCVRP), the Multi-Modal Vehicle Routing Problem (MMVRP), the Pick-Up and Delivery Vehicle Routing Problem (PDVRP), and the Energy Routing Problems (ERP) [39]. In many of these models, the objectives presented are not in conflict, because by minimizing the total distance or routing time the fuel consumption is also reduced and with this the amount of polluting emissions.

The main objective of this paper is to integrate an environmental factor into a mixed integer linear program to make decisions in a solid waste collection system used in a set of islands. This environmental factor represents the accumulation of residues at the selected collection points and its variation through time. The model is presented as a conflicting biobjective problem because when the transportation cost is minimized, the environmental impact caused by the accumulation of this solid waste is increased. A Pareto front is obtained using two classical methods of solution: epsilonconstraint method and weighted sum method.

The paper is organized as follows. Section 2 describes the problem, Section 3 presents the mathematical formulation, Section 4 explains the application of the model to an instance taken from real data in a set of islands in southern Chile, Section 5 gives an overview of the solving methods that were used, Section 6 presents results and discussion, and finally in Section 7 conclusions are discussed.

\section{Problem Description}

This paper continues the work presented by Miranda et al. [13], where a set of islands and isolated sectors are considered, each one with a determined number of potential collection points to be selected. Routes have to be determined, subject to capacity restrictions and time windows, beginning and ending in a deposit, to minimize transportation cost in a defined time horizon.

In the proposal in this paper as main contribution, an additional objective is implemented, looking for the minimization of the environmental impact caused by the quantity of solid waste generated at the islands, affected by the selected pattern that represents the frequency of visits and the number of collection sites selected in each island. We consider that the solid waste generated is stored in a specific area, determined by the volume of waste generated daily. We study the effect in a weekly horizon, derived from the generation of leachate in the waste and the potential content of total coliforms. We assume that weather data is constant through the duration of the study, since this affects the kinetics of population growth of coliforms.

\section{Model Formulation}

The WCSD model introduced in Section 2 is formulated as a mixed integer problem, where collection sites have to be selected at each island, selects a visit pattern for each collection site, and determines the visit sequence every period, taking into account the capacity restrictions and time windows for each point, to obtain a Pareto front that presents the possible solutions for the minimization of the transportation cost and also the environmental impact.

3.1. Assumptions. In order to simplify the scenario of the system, the following assumptions were considered: planning horizon is weekly and Sundays are not considered as collection days. Selected collection sites are visited at least once a 
TABLE 1: Visit patterns $p$ considering visit day $t$ and weekly frequency.

\begin{tabular}{|c|c|c|c|c|c|c|c|}
\hline \multirow{2}{*}{ Collection pattern } & \multicolumn{6}{|c|}{ Day $(t)$} & \multirow{2}{*}{ Weekly frequency } \\
\hline & 1 & 2 & 3 & 4 & 5 & 6 & \\
\hline 1 & $x$ & & & & & & 1 \\
\hline 2 & & $x$ & & & & & 1 \\
\hline 3 & & & $x$ & & & & 1 \\
\hline 4 & & & & $\times$ & & & 1 \\
\hline 5 & & & & & $\times$ & & 1 \\
\hline 6 & & & & & & $x$ & 1 \\
\hline 7 & $x$ & & & $x$ & & & 2 \\
\hline 8 & & $x$ & & & $x$ & & 2 \\
\hline 9 & & & $x$ & & & $x$ & 2 \\
\hline 10 & $x$ & & $x$ & & $x$ & & 3 \\
\hline 11 & & $x$ & & $x$ & & $x$ & 3 \\
\hline 12 & $\times$ & $x$ & $x$ & $x$ & $x$ & $x$ & 6 \\
\hline
\end{tabular}

week, and this pattern is repeated every week. All routes start and end at the deposit, in Dalcahue. Time windows are from 6:00 to 20:00 for every collection site. Waste generation is constant through the duration of the study, and the amount of waste generated in an island is divided homogenously by the selected collection sites. Navigation speed is considered a constant with value equal to 9 knots. Transportation cost is given by the navigation cost also considered a constant with value equal to $\$ 3,840$ CLP per nautical mile. The capacity of the barge is 90 cubic meters. Operation time for arriving, picking, and departing at every point is 0.5 hours. For the environmental parameter, an average precipitation value of $1665 \mathrm{~mm}$ /year and solid waste compactness value of 0.25 are considered, and the superficial area occupied by the solid waste considers that waste is accumulated to 1-meter height. The visit frequency is given according to the collection patterns shown in Table 1.

\subsection{Parameters and Decision Variables}

Sets, Indexes, and Parameters. $H$ is the set of islands to be served. $N$ is set of nodes, including potential waste collection sites and the depot. $p$ is index for visit pattern $(p=1, \ldots, 12)$. $t$ is index for time period or day $(t=1, \ldots, 6) . i, j$ are indexes for nodes $(i \in|N|)$, where $i_{0}$ is the depot. $v$ is index for island $(v \in H) . \Omega_{v}$ is set of potential locations for waste collection in island $v . k$ is index indicating the number of selected locations for waste disposal on an island $\left(k=1, \ldots,\left|\Omega_{v}\right|\right.$, for each island $v) . c_{i j}$ is transportation cost from node $i$ to node $j . r_{p t}$ is as follows:

$$
\begin{aligned}
& r_{p t} \\
& = \begin{cases}1, & \text { if pattern } p \text { contemplates collection happens in day } t \\
0, & \text { otherwise. }\end{cases}
\end{aligned}
$$

$q_{v p t}^{k}$ is amount of waste to be collected on period $t(t=$ $1, \ldots, T)$ from any collection site on island $v$, in the case that pattern $p$ is selected $(p=1, \ldots, P)$, and the island is served by using $k$ waste collection sites $\left(k=1, \ldots,\left|\Omega_{v}\right|\right)$. This parameter is computed for each possible value of $k$ and for each visit pattern $p$, as a function of the total weekly generated waste for island $v$. If $D_{v}$ is the weekly generated waste for island $v$, then

$$
q_{v p t}^{k}=\frac{D_{v}}{\left(k \cdot \sum_{t=1}^{T} r_{p t}\right)} \cdot r_{p t},
$$

where $D_{v}$ is amount of solid waste generated weekly in island $v$. $d$ is operating time for pick-up at each collection site. $t_{i j}$ is travel time from node $i$ to node $j$. CAP is capacity of the barge $\left(\mathrm{m}^{3}\right) . M$ is a large constant. $a_{i}$ and $b_{i}$ are earliest and latest times for arrival at each node $i . H_{v k p}$ is environmental parameter determined for each node or dock of each island $v$ according to the $k$ collection sites selected and the collection pattern $p$ assigned. The calculation of this parameter is based on the kinetics of bacterial growth in (4) [40], in this case for total coliforms. To obtain the initial number of bacteria, a hydric balance equation is used in (3) [41, 42], where the leachate generated in a day is determined by multiplying the average precipitation at site $P$, the area occupied by the solid waste $A$, and the compactness degree of solid waste $S$, divided by the time $t_{a}$. The number of total coliforms, MPNCTot, found in a milliliter of leachate is assumed to be a generalized parameter [7]:

$$
\begin{aligned}
N_{0} & =\frac{P \cdot A \cdot S}{t_{a}} \cdot \text { MPNCTot } \\
H_{v k p} & =\frac{N_{0}}{k} \cdot 2^{t / T},
\end{aligned}
$$

where $N_{0}$ is initial number of total coliforms present in solid waste leachate. $P$ is average precipitation per year. $A$ is area occupied by solid waste. $S$ is solid waste compactness. $t_{a}$ are seconds in a year. $t$ is accumulation time of the solid waste. $T$ is environment temperature. $k$ is the number of collection sites $k$ selected. MPNCTot is the number of total coliforms found in a milliliter of leachate (most probable number). 
Decision Variables. Consider the following:

$$
\begin{aligned}
& x_{i p}= \begin{cases}1, & \text { if collection site at node } i \text { is visited } \\
\text { according to visit pattern } p \\
0, & \text { otherwise }\end{cases} \\
& z_{i}= \begin{cases}1, & \text { if node } i \text { is selected as collection site } \\
0, & \text { otherwise }\end{cases} \\
& U_{v k} \\
& = \begin{cases}1, & \text { if island } v \text { is served using } k \text { collection sites } \\
0, & \text { otherwise }\end{cases}
\end{aligned}
$$

$$
\begin{array}{ll}
\min & Z_{1}=\sum_{t=1}^{T} \sum_{i \in N} \sum_{j \in N / i \neq j} c_{i j} \cdot Y_{i j t} \\
\min & Z_{2}=\sum_{i \in v} \sum_{k} \sum_{p} L_{i p}^{k} \cdot H_{v k p}
\end{array}
$$$$
Y_{i j t}= \begin{cases}1, & \text { if node } j \text { is visited immediatly after } \\ & \text { node } i \text { during operation period } t \\ 0, & \text { otherwise }\end{cases}
$$$$
L_{i p}^{k}= \begin{cases}1, & \text { if node } i \text { is visited according to visit } \\ & \text { pattern } p \text { using } k \text { collection sites } \\ 0, & \text { otherwise }\end{cases}
$$

Auxiliary Variables. $W_{i t}$ is the amount of waste to be collected from the collection site at node $i$ on period or day $t . T_{i t}$ is arrival time to the node $i$ or the depot on period $t$.

3.3. Biobjective Optimization Model. Consider the following:

$$
\begin{aligned}
& \text { Subject to: } \quad Z_{i}=\sum_{p=1}^{P} x_{i p} \quad \forall i \in N / i \neq i_{0} \\
& \sum_{p=1}^{P} x_{i p}=0 \quad \forall i \in N / i=i_{0} \\
& \sum_{i \in \Omega_{v}} Z_{i}=\sum_{k=1}^{\left|\Omega_{v}\right|} k \cdot U_{v k} \quad \forall v \in H \\
& \sum_{i \in \Omega_{v}} Z_{i} \geq 1 \quad \forall v \in H \\
& \sum_{i \in N-\left\{\Omega_{v}\right\}} Z_{i}=0 \quad \forall v \in H \\
& \sum_{k=1}^{\left|\Omega_{v}\right|} U_{v k}=1 \quad \forall v \in H \\
& W_{i t} \leq \sum_{p=1}^{P} q_{v p t}^{k} \cdot X_{i p}+\mathrm{CAP} \cdot\left(U_{v k}-1\right) \quad \forall t=1, \ldots, T, \forall v \in H, \forall i \in \Omega_{v}, \forall k=1, \ldots,\left|\Omega_{v}\right| \\
& \mathrm{CAP} \geq \sum_{i \in N-\left\{i_{0}\right\}} W_{i t} \quad \forall t=1, \ldots, T \\
& \sum_{p=1}^{P} X_{i p} \cdot r_{p t}=\sum_{j \in N, j \neq i} Y_{i j t} \quad \forall t=1, \ldots, T, \forall i \in N / i \neq i_{0} \\
& \sum_{i \in N-\left\{i_{0}\right\}} Y_{i_{0} i t} \leq 1 \quad \forall t=1, \ldots, T \\
& \sum_{\substack{j \in N \\
i \neq j}} Y_{j i t}=\sum_{\substack{j \in N \\
i \neq j}} Y_{i j t} \quad \forall i \in N, \forall t=1, \ldots, T
\end{aligned}
$$




$$
\begin{aligned}
& \sum_{k=1}^{\left|\Omega_{v}\right|} L_{i p}^{k} \cdot k=X_{i p} \quad \forall v \in H, \forall p=1, \ldots, P, \forall i \in N \\
& \sum_{k=1}^{\left|\Omega_{v}\right|} L_{i p}^{k} \leq Z_{i} \quad \forall p=1, \ldots, P, \forall i \in N \\
& \sum_{k=1}^{\left|\Omega_{v}\right|} \sum_{p=1}^{P} q_{v p t}^{k} \cdot L_{i p}^{k} \leq W_{i t} \quad \forall v \in H, \forall i \in N, \forall t=1, \ldots, T \\
& U_{v k}+X_{i p}-1 \leq L_{i p}^{k} \quad \forall v \in H, k=1, \ldots,\left|\Omega_{v}\right|, \forall i \in N, \forall p=1, \ldots, P \\
& a_{i} \leq T_{i t} \leq b_{i} \quad \forall i \in N, \forall t=1, \ldots, T \\
& T_{j t} \geq a_{i_{0}}+t_{i_{0} j}-\left(1-Y_{i_{0} j t}\right) \cdot M \quad \forall t=1, \ldots, T, \forall j \in N / j \neq i_{0} \\
& T_{j t} \geq T_{i t}+t_{i j}+d-\left(1-Y_{i j t}\right) \cdot b_{j} \quad \forall t=1, \ldots, T, \forall j \in N / j \neq i_{0} \\
& Z_{i}, X_{i p} \in\{0,1\} \quad \forall p=1, \ldots, P, \forall i \in N / i \neq i_{0} \\
& W_{i t}, T_{i t} \geq 0 \quad \forall i \in N, \forall t=1, \ldots, T \\
& Y_{i j t} \in\{0,1\} \quad \forall i, j \in N, j \neq i, \forall t=1, \ldots, T \\
& U_{v k} \in\{0,1\} \quad \forall v \in H, k=1, \ldots,\left|\Omega_{v}\right| \\
& L_{i p}^{k} \in\{0,1\} \quad \forall p=1, \ldots, P, \forall i \in N, k=1, \ldots,\left|\Omega_{v}\right| .
\end{aligned}
$$

The first objective function (6) minimizes total transportation costs in a predefined time horizon. The second one (7) minimizes the environmental impact according to the collection pattern $p$ assigned and the number of collection sites $k$ that will be served. Constraints (8) state that if a collection site $i$ is selected, a single collection pattern $p$ must be designated, except for origin node, for which no pattern is assigned (9). Constraints (10) relate selected nodes $\left(Z_{i}\right)$ to the number of collection sites selected in each island $v\left(U_{v k}\right)$. Constraints (11) ensure that at least one node is selected per island. Constraints (12) avoid nodes $i$ that do not belong to island $v$ to be selected. Constraints (13) indicate that each island $v$ has to be served only with one option of number of $k$ collection sites selected. Equation (14) states lower bounds to the waste volume collected from each collection site $i$ and for each period $t$, depending on the selected visit pattern $p$ $\left(X_{i p}\right)$. Equation (15) states capacity restrictions. Constraints (16) state that if node $i$ is visited with collection pattern $p$, which contemplates day $t$, then this node has to be visited from another node $i$ or from the deposit. Constraints (17) indicate that every day $t$ there can be only one collection route. Equation (18) observes that if node $i$ is visited in day $t$, then barge must travel from node $i$ to node $j$ in the same day $t$. Restrictions (19) relate collection pattern $p$, selected node $i$, and number of selected collection sites $k$ to the variable $L_{i p}^{k}$. Equation (20) relates $Z_{i}$ to $L_{i p}^{k}$. Constraints (21) limit the decision variable of a node $i$ related to the amount of waste generated in that site with the volume of collected waste in node $i$ on day $t$. Restrictions (22) activate decision variable
$L_{i p}^{k}$ if a collection pattern $p$ is selected for node $i$ with island $v$ served with $k$ collection sites and add environmental impact; otherwise environmental impact in a node that is not selected is not taken into account. Equation (23) establishes time windows. Restrictions (24) and (25) bound the arrival time at each node $j$ as a function of the accumulated time on the navigation route, the waste loading times at previously visited collection points, and the activation of routing variables $Y_{i j t}$. Constraints (26)-(30) determine decision variables domains.

Equations (9), (19)-(22), and (30) were added to the original mathematical model of Miranda et al. [13] to add the environmental factor. Constraints (9), (11), and (12) were added to ensure correct functioning of the program in the optimization software.

\section{Case Study}

The case study is centered in an archipelago in the southern area of Chile, in Chiloe and Palena provinces. Dalcahue is determined to be the deposit, starting and ending point of all collection routes. The original problem establishes a set of 20 islands and 1 isolated sector, each one with a determined number of potential collection sites, with a total of 34 nodes. In this paper, an instance taken from that problem is presented to apply the biobjective model. For the environmental impact calculation, it is supposed that solid waste is gathered at each island in uncontrolled dumpsites and reaches a 1-meter height. The proposed instance has six islands and 13 nodes (Table 2), illustrated in Figure 1. 
TABLE 2: Name of the islands, waste generation per day in 2015, and potential collection sites for each island [13].

\begin{tabular}{lccc}
\hline & Island & Waste generation per day $\left(\mathrm{m}^{3}\right)$ & Number of potential collection sites \\
\hline 1 & Dalcahue & 0.00 & 1 \\
2 & Butachauques & 1.58 & 3 \\
3 & Tranqui & 1.29 & 3 \\
4 & Mechuque & 0.98 & 2 \\
5 & Caucahue & 1.01 & 2 \\
6 & Chelin & 0.83 & 2 \\
\hline
\end{tabular}

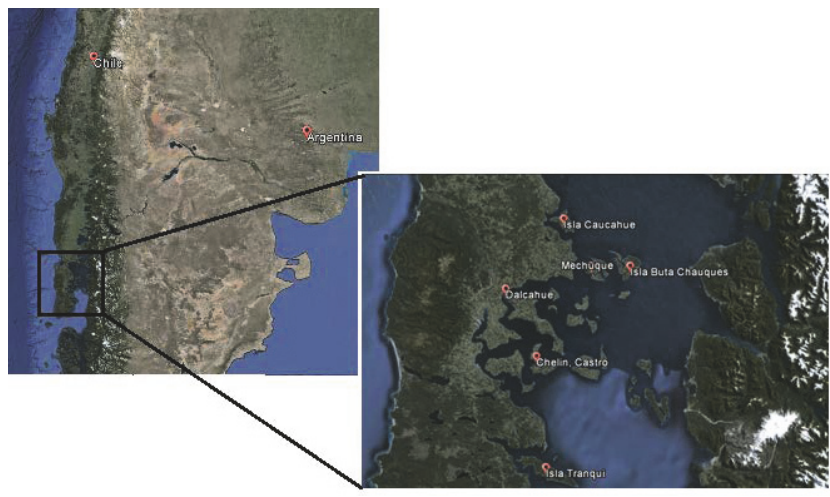

FIGURE 1: Location of the islands, obtained with Google Earth ${ }^{\mathrm{TM}}$.

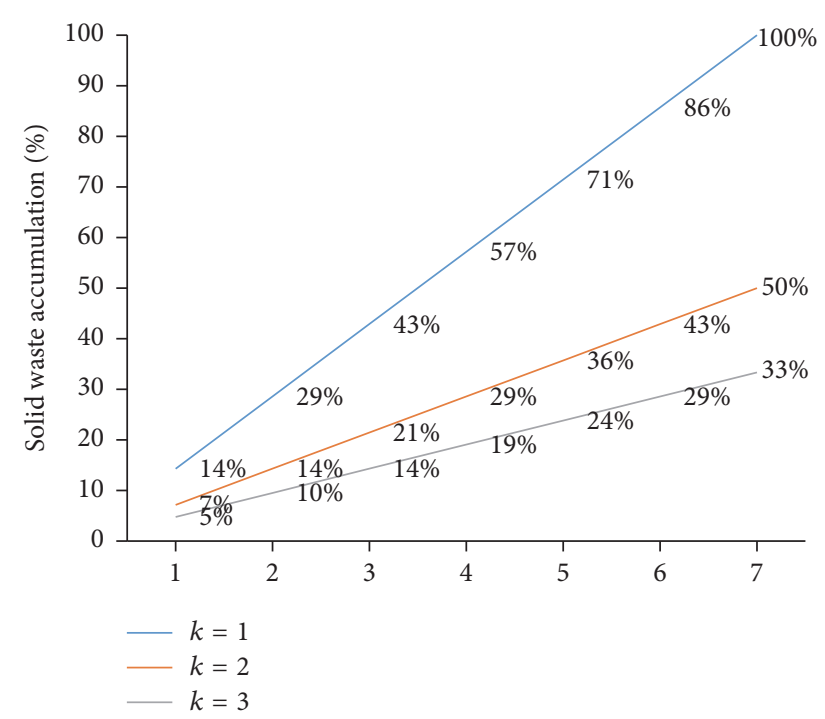

Figure 2: Solid waste accumulation per day $t$ for $p=1, \ldots, 6$ and $k=1,2,3$.

Accumulation patterns of the solid waste per day are shown in Figure 2 for nodes 1 to 6, in Figure 3 for nodes 7 to 9, in Figure 4 for nodes 10 and 11, and in Figure 5 for node 12.

\section{Methods}

Two classical solving methods were selected to obtain the Pareto front, that is, the weighted sum method and the epsilon-constraint method. The weighted sum method is described by Deb [43] as a simple, easy, and intuitive

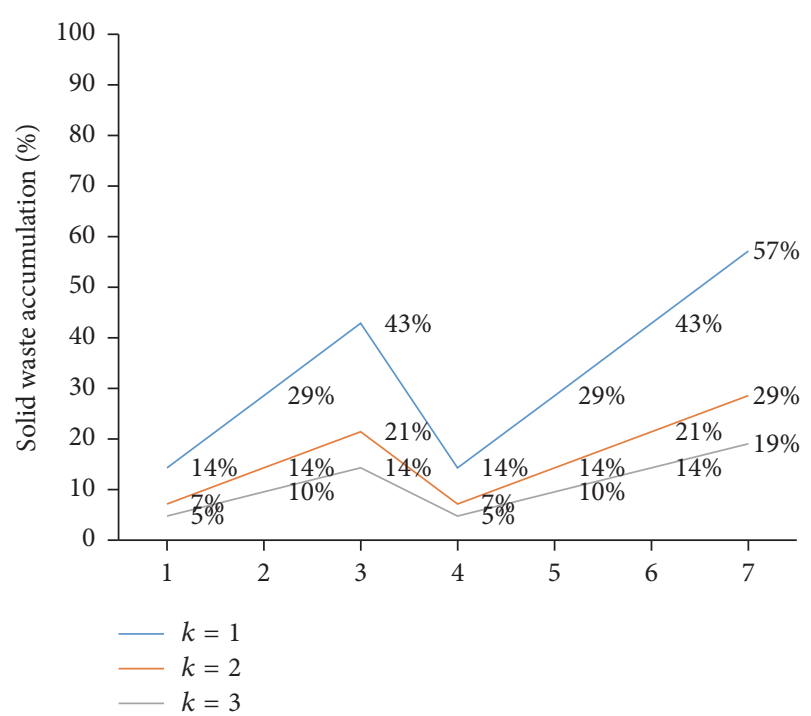

Figure 3: Solid waste accumulation per day $t$ for $p=7,8,9$ and $k=1,2,3$.

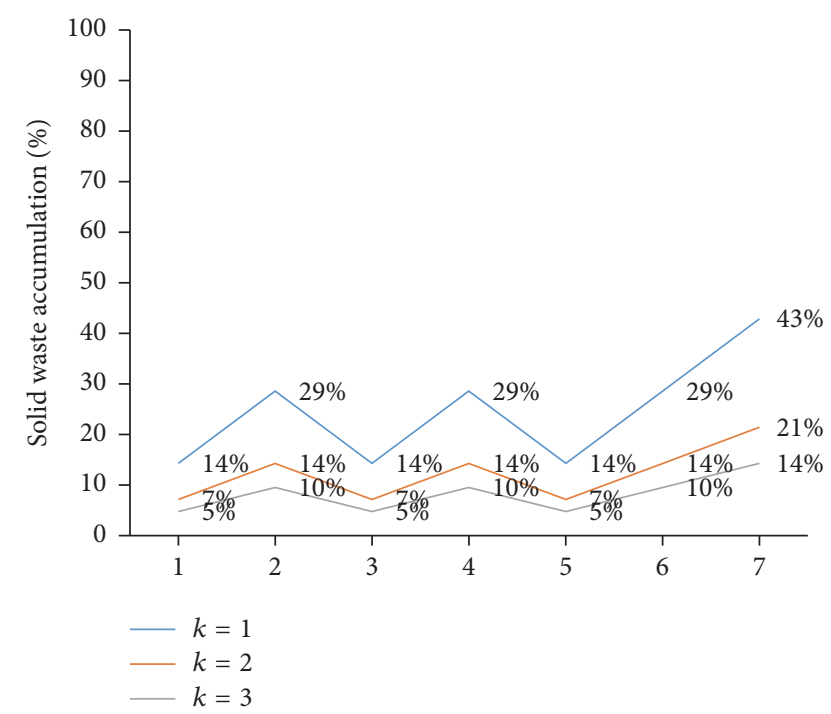

FIGURE 4: Solid waste accumulation per day $t$ for $p=10,11$ and $k=1,2,3$.

technique, where a value of importance is assigned to each objective, according to predefined interests of the decisionmakers. Importance is related to $\alpha$ and all the objectives are combined as a single objective in the same equation (31). In 
TABLE 3: Results for total transportation cost and environmental impact using the weighted sum technique.

\begin{tabular}{lccc}
\hline$\alpha$ & $\begin{array}{c}\text { Transportation cost } \\
\text { (CLP) }\end{array}$ & $\begin{array}{c}\text { Environmental impact } \\
\text { (most probable number of } \\
\text { coliforms) }\end{array}$ & $\begin{array}{c}\text { Computational } \\
\text { time (s) }\end{array}$ \\
\hline $0^{*}$ & $2,137,728$ & $104,023,711.78$ & $00: 06.2$ \\
0.2 & $1,800,576$ & $58,567,911.47$ & $01: 14.4$ \\
0.3 & $1,416,960$ & $134,553,727.11$ & $02: 40.4$ \\
0.4 & $1,416,960$ & $134,553,727.11$ & $00: 34.2$ \\
0.5 & $1,416,960$ & $134,553,727.11$ & $00: 15.3$ \\
0.6 & $1,416,960$ & $134,553,727.11$ & $00: 18.7$ \\
0.7 & $1,281,408$ & $264,665,436.62$ & $00: 33.4$ \\
0.8 & $1,120,128$ & $526,591,888.49$ & $00: 21.3$ \\
0.9 & $1,086,336$ & $614,943,387.54$ & $00: 06.2$ \\
1 & $1,086,336$ & $614,943,387.54$ & $00: 06.2$ \\
\hline
\end{tabular}

* This solution is dominated and therefore is not shown in the Pareto front.

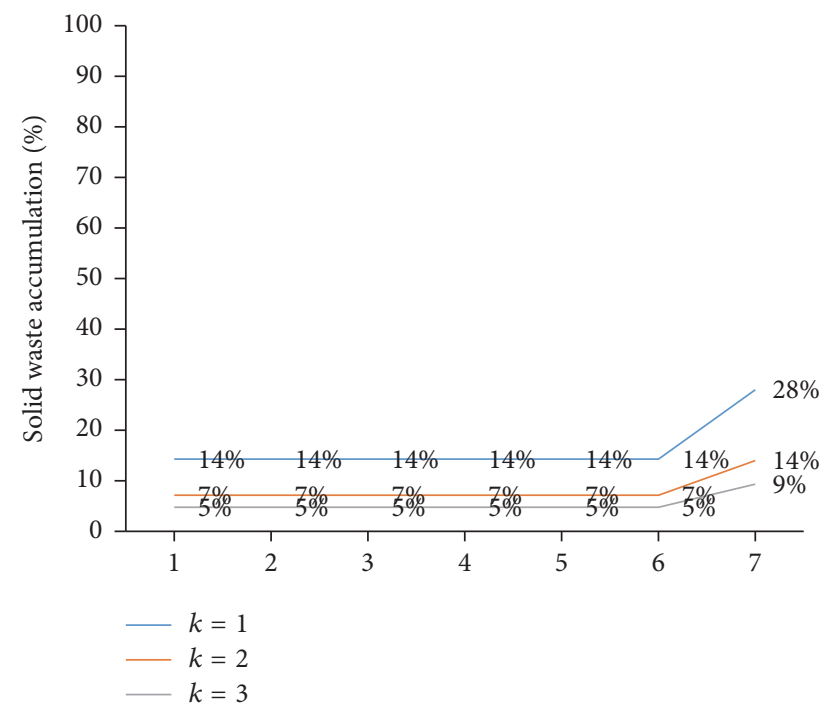

FIgURE 5: Solid waste accumulation per day $t$ for $p=12$ and $k=$ $1,2,3$.

this method, a normalization of the objectives is required because the objectives often present different magnitudes and units. In (32), the normalization method that was used for this case is as follows:

$$
\begin{aligned}
\min & Z \\
= & \alpha \cdot \sum_{t=1}^{T} \sum_{i \in N} \sum_{j \in N / i \neq j} c_{i j} \cdot Y_{i j t}+(1-\alpha) \\
& \cdot \sum_{i \in v} \sum_{k} \sum_{p} L_{i p}^{k} \cdot H_{v k p} .
\end{aligned}
$$

The first part of the function, which minimizes total transportation cost, is $f_{1}$ and the second part, which looks for the minimization of the environmental impact, is $f_{2}$ :

$$
\min \quad Z=\alpha \cdot \frac{f_{1}-f_{1}^{\min }}{f_{1}^{\max }-f_{1}^{\min }}+(1-\alpha) \cdot \frac{f_{2}-f_{2}^{\min }}{f_{2}^{\max }-f_{2}^{\min }} .
$$

The lowest value that transportation cost could take is represented by $f_{1}^{\min }(\alpha=1)$. This means that no importance is given to the environmental impact, in which case the maximum level that environmental impact may get is $f_{2}^{\max }$. The lowest value of environmental impact is expressed with $f_{2}^{\min }(\alpha=0)$ and represents the fact that no importance is given to the total transportation cost $\left(f_{1}^{\max }\right)$ and that is the maximum level that transportation cost may take. Values $f_{1}^{\min }$ and $f_{2}^{\max }$ were obtained minimizing total transportation cost $(\alpha=1)$, while $f_{2}^{\min }$ and $f_{1}^{\max }$ were the result of minimizing environmental impact $(\alpha=0)$. Values of $\alpha$ were varied in a range between 0 and 1 .

The epsilon-constraint method formulates the objective function selecting only one of the objectives (33) and setting the other objectives as constraints (34), using specified values for the value of $\varepsilon$ [43]:

$$
\begin{array}{r}
\min \quad Z=\sum_{t=1}^{T} \sum_{i \in N} \sum_{j \in N / i \neq j} c_{i j} \cdot Y_{i j t} \\
\text { Subject to: } \quad \sum_{i \in v} \sum_{k} \sum_{p} L_{i p}^{k} \cdot H_{v k p} \leq \varepsilon .
\end{array}
$$

According to Deb [43], to determine the value of $\varepsilon$, it is necessary to have previous knowledge of the problem and the range where values will be changing.

\section{Results and Discussion}

The optimization model was solved using commercial optimization software (GAMS-CPLEX) using both methods: the weighted sum method and the epsilon-constraint method. Routes, arriving times, sequence and frequency, total transportation cost, and environmental impact were obtained for each case. In Table 3, total transportation cost, environmental impact, and computational time for several $\alpha$ values (0-1) are shown. Figure 6 shows the Pareto front obtained using the weighted sum technique. Even though $\alpha$ varied 10 times, only five different solutions were obtained. 
TABLE 4: Visit sequences and schedules for $\alpha=0.2$ using the weighted sum method.

\begin{tabular}{|c|c|c|c|}
\hline & Island & Waste collection site & Arrival time \\
\hline \multirow{3}{*}{ Monday } & Tranqui & 1 & 06:00 \\
\hline & Chelin & 2 & 09:22 \\
\hline & Dalcahue (depot) & - & $12: 02$ \\
\hline \multirow{4}{*}{ Tuesday } & Mechuque & 2 & 06:00 \\
\hline & Butachauques & 1 & 08:06 \\
\hline & Caucahue & 2 & $10: 17$ \\
\hline & Dalcahue (depot) & - & $14: 06$ \\
\hline \multirow{3}{*}{ Wednesday } & Chelin & 2 & 06:00 \\
\hline & Tranqui & 1 & 09:58 \\
\hline & Dalcahue (depot) & - & $15: 08$ \\
\hline \multirow{4}{*}{ Thursday } & Caucahue & 2 & 06:00 \\
\hline & Butachauques & 1 & 08:11 \\
\hline & Mechuque & 2 & 09:59 \\
\hline & Dalcahue (depot) & - & $12: 06$ \\
\hline \multirow{3}{*}{ Friday } & Tranqui & 1 & 06:00 \\
\hline & Chelin & 2 & 09:22 \\
\hline & Dalcahue (depot) & - & $12: 02$ \\
\hline \multirow{4}{*}{ Saturday } & Caucahue & 2 & 06:00 \\
\hline & Butachauques & 1 & $08: 11$ \\
\hline & Mechuque & 2 & 09:59 \\
\hline & Dalcahue (depot) & - & $12: 06$ \\
\hline
\end{tabular}

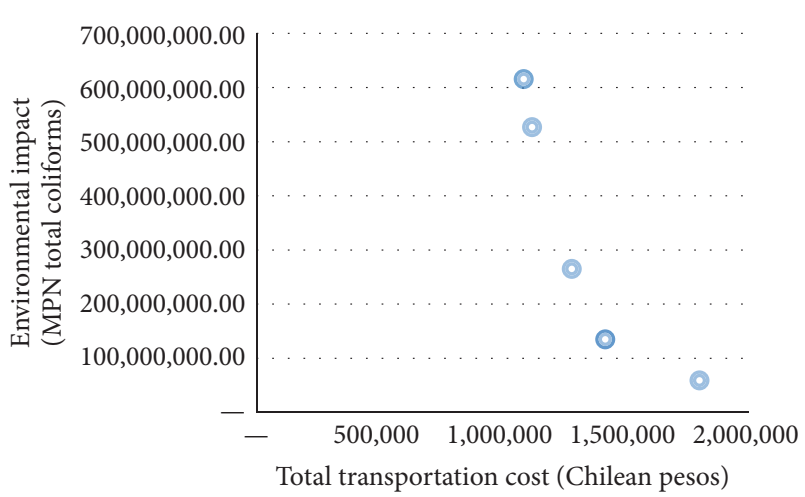

FIgURE 6: Pareto front obtained using weighted sum method.

For this solving method, results for $\alpha=0.2$ are presented in Table 4 and illustrated in Figure 7, according to the keys in Table 2. In this case, $\alpha=0.2$ represents the most favorable scenario for the environmental impact minimization, while the transportation cost being considered less important.

In Table 5, total transportation cost, environmental impact, and computational time for epsilon-constraint method are shown. With this method, the Pareto front presents nine different solutions, illustrated in Figure 8.

The best case scenario for the minimization of the environmental impact was found with $\varepsilon=1.3 E+8$. The routes and arrival times for this solution are presented in Table 6 and illustrated in Figure 9, according to the keys in Table 2.

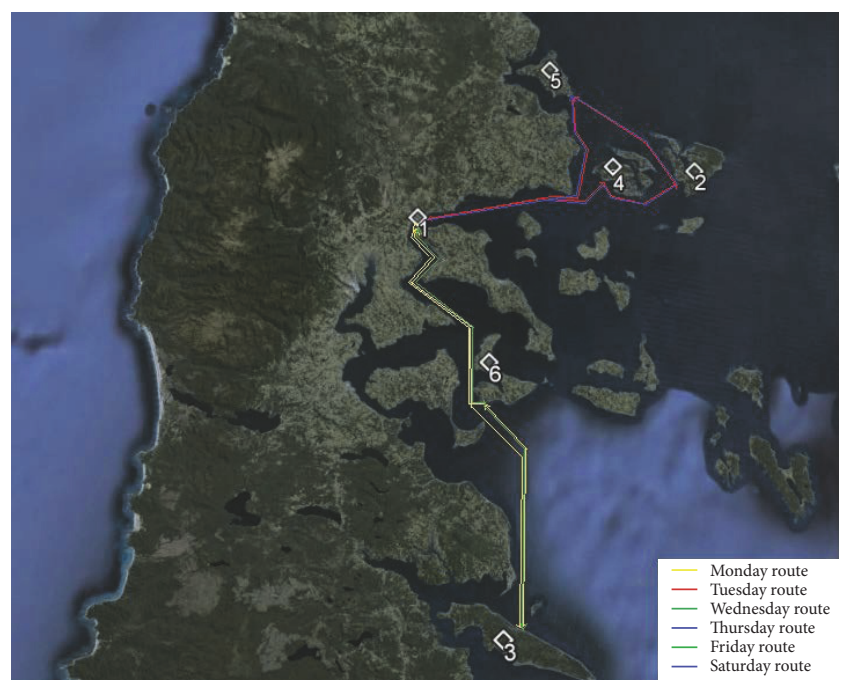

FIGURE 7: Navigation routes for $\alpha=0.2$.

\section{Conclusions}

This paper shows the integration of an environmental factor to a mixed integer lineal programming model for the design of a solid waste collection system to serve a set of islands and isolated points, in Chiloe and Palena in southern Chile. An instance with six islands and thirteen nodes is studied. The environmental impact is calculated according to the 
TABLE 5: Results of total transportation cost and environmental impact using the epsilon-constraint method.

\begin{tabular}{lccc}
\hline$\varepsilon$ & $\begin{array}{c}\text { Transportation cost } \\
\text { (CLP) }\end{array}$ & $\begin{array}{c}\text { Environmental impact } \\
\text { (most probable number of } \\
\text { coliforms) }\end{array}$ & $\begin{array}{c}\text { Computational } \\
\text { time }(\mathrm{s})\end{array}$ \\
\hline $1.0 E+8$ & Infeasible & Unbounded & $16: 41$ \\
$1.3 E+8$ & $1,621,248$ & $121,424,816.95$ & $03: 24.9$ \\
$2.0 E+8$ & $1,416,960$ & $134,553,727.11$ & $00: 33.4$ \\
$2.5 E+8$ & $1,366,272$ & $205,855,113.03$ & $06: 02.8$ \\
$3.0 E+8$ & $1,281,408$ & $264,665,436.62$ & $01: 16.6$ \\
$3.5 E+8$ & $1,261,056$ & $348,795,259.26$ & $01: 34.5$ \\
$4.5 E+8$ & $1,211,136$ & $367,188,014.01$ & $01: 22.2$ \\
$5.0 E+8$ & $1,193,856$ & $466,645,132.27$ & $01: 04.9$ \\
$6.0 E+8$ & $1,120,128$ & $526,591,888.49$ & $00: 22.3$ \\
$6.5 E+8$ & $1,086,336$ & $614,943,387.54$ & $00: 05.7$ \\
\hline
\end{tabular}

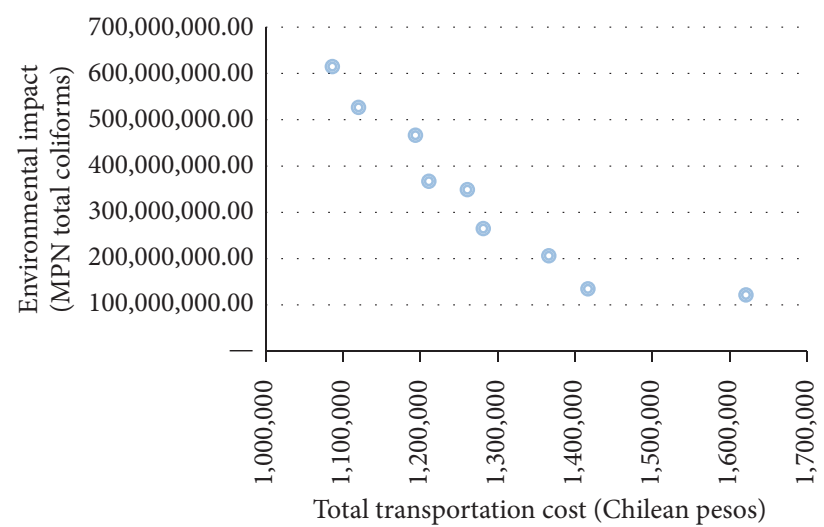

Figure 8: Pareto front obtained using the epsilon-constraint method.

collection pattern $p$ selected at each node $i$ and the number of selected collection sites $k$ at each island $v$. According to these patterns and some assumptions such as average precipitation and environmental temperature, the amount of leachate generated per day is calculated. These leachates are the medium where it is assumed that coliform bacteria grow following kinetics depending on time and temperature. This scenario presents a biobjective problem with conflicting goals. On one hand, a collection pattern with fewer visits to the sites is cheaper in terms of transportation costs, but, on the other hand, this produces an accumulation of waste for more time giving conditions for leachate production and bacteria proliferation with a consequent greater environmental impact. For this kind of problems, the aim is to obtain a Pareto front as large and diverse as possible to give options of solutions to the decision-maker. In this paper, two classical solving methods were applied: the weighted sum method and the epsilon-constraint method. In the results presented, it can be observed that even though weighted sum technique presents advantages, mainly in computational time, only five different solutions were generated, whereas with epsilonconstraint technique, nine dissimilar results were obtained. Each one of those solutions has to be evaluated considering

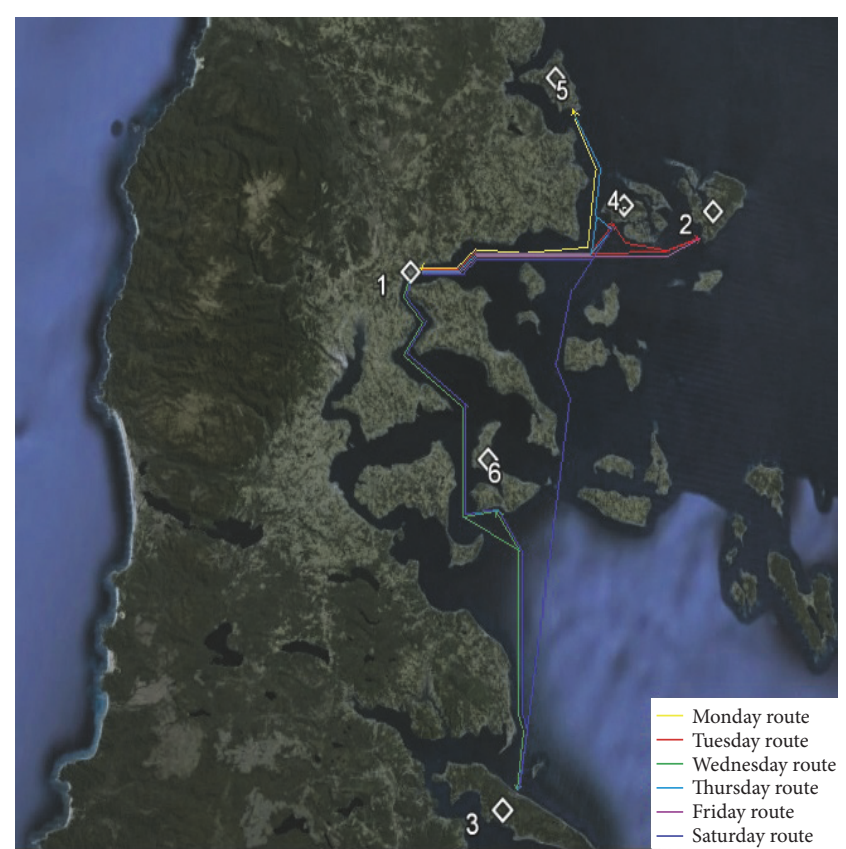

Figure 9: Navigation routes for $\varepsilon=1.3 E+8$.

advantages and disadvantages related to aspects not included in the model and taking into consideration aspects that might be predefined such as a budget for the waste collection system or national laws that establish maximum allowable limits for bacterial pollution.

As future work in the environmental aspect, the leachate characterization in situ may give a better and more realistic understanding of the situation in Chiloe region. Regarding the solid waste collection system, a preventive phase would be recommended, which includes the environmental education and the reuse and recycling of materials, because this would dramatically decrease the amount of waste to be transported to landfills, diminishing total transportation cost and environmental impact. Also, it would be important to consider the internal routing problem at each island and adding these 
TABLE 6: Visit sequences and schedule for $\varepsilon=1.3 E+8$ using the epsilon-constraint method.

\begin{tabular}{|c|c|c|c|}
\hline & Island & Waste collection site & Arrival time \\
\hline \multirow{2}{*}{ Monday } & Caucahue & 2 & 06:00 \\
\hline & Dalcahue (depot) & - & 09:49 \\
\hline \multirow{3}{*}{ Tuesday } & Mechuque & 2 & $06: 00$ \\
\hline & Butachauques & 1 & $07: 48$ \\
\hline & Dalcahue (depot) & - & 11:01 \\
\hline \multirow{3}{*}{ Wednesday } & Tranqui & 1 & 06:00 \\
\hline & Chelin & 2 & $09: 58$ \\
\hline & Dalcahue (depot) & - & $12: 02$ \\
\hline \multirow{3}{*}{ Thursday } & Mechuque & 2 & 06:00 \\
\hline & Caucahue & 2 & $07: 49$ \\
\hline & Dalcahue (depot) & - & $10: 58$ \\
\hline \multirow{2}{*}{ Friday } & Butachauques & 1 & $06: 00$ \\
\hline & Dalcahue (depot) & - & 09:53 \\
\hline \multirow{4}{*}{ Saturday } & Chelin & 2 & 06:00 \\
\hline & Tranqui & 1 & 09:18 \\
\hline & Mechuque & 2 & $15: 01$ \\
\hline & Dalcahue (depot) & - & $17: 48$ \\
\hline
\end{tabular}

costs to the overall mathematical model. With regard to the operation research area, metaheuristics could be explored for the resolution of these types of problems for larger instances, reducing computational times.

\section{Conflicts of Interest}

The authors declare that they have no conflicts of interest.

\section{Acknowledgments}

The authors would like to acknowledge the support that the Mexican National Council for Science and Technology (CONACYT-México) gives by providing scholarships for graduate studies and studies abroad. Also they would like to acknowledge the Chilean National Foundation for Scientific \& Technological Development (FONDECYT-Chile) for its support (Project no. 1140811).

\section{References}

[1] L. White, "The historical roots of our ecologic crisis," Science, vol. 155, no. 3767, pp. 1203-1207, 1967.

[2] L. Lorentzen, Ética Ambiental, Universidad Iberoamericana, Puebla, Mexico, 2001.

[3] CONAMA (Comisión Nacional de Medio Ambiente), Política de Gestión Integral de Residuos Sólidos, Gobierno de Chile, Chile, 2005.

[4] E. Irigoyen, Economía Ambiental, Universidad Iberoamericana, Puebla, Mexico, 2001.

[5] A. Jaime and P. R. O. Tinoco-Lopez, "Métodos de valuación de externalidades ambientales provocadas por obras de ingeniería," Ingeniería, Investigación y Tecnología, vol. 7, no. 2, pp. 105-119, 2006.
[6] M. L. MacDonald, "Solid waste management models: a state of the art review," The Journal of Resource Management and Technology, vol. 23, no. 2, pp. 73-83, 1996.

[7] M. Espinosa Llorens, M. López, A. Pellón et al., “Análisis del comportamiento de los lixiviados generados en un vertedero de residuos sólidos municipales de la ciudad de la Habana," Revista Internacional de Contaminación Ambiental, vol. 26, no. 4, pp. 313-325, 2010.

[8] A. Sbihi and R. W. Eglese, "Combinatorial optimization and Green logistics," Annals of Operations Research, vol. 175, pp. 159175, 2010.

[9] M. K. Nganda, Mathematical Models in Municipal Solid Waste Management [MSc. thesis], Department of Mathematical Sciences, Chalmers University of Technology and Göteborg University Göteborg, Sweden, 2007.

[10] E. Kondili, "Review of optimization models in the pollution prevention and control," Computer Aided Chemical Engineering, vol. 20, no. C, pp. 1627-1632, 2005.

[11] M. N. Mehr and R. G. McGarvey, "Planning solid waste collection with robust optimization: location-allocation, receptacle type, and service frequency," Advances in Operations Research, vol. 2017, pp. 1-14, 2017.

[12] T. Stypka, Critical Review of Municipal Solid Waste Management Models, Cracow University of Technology, Institute of Thermal Processes and Air Protection, Cracow, Poland, 2002.

[13] P. A. Miranda, C. A. Blazquez, R. Vergara, and S. Weitzler, "A novel methodology for designing a household waste collection system for insular zones," Transportation Research Part E: Logistics and Transportation Review, vol. 77, pp. 227-247, 2015.

[14] F. Beijoco, V. Semiao, and Z. Zsigraiová, Optimization of a Municipal Solid Waste Collection and Transportation System, Department of Mechanical Engineering, Technical University of Lisbon, Instituto Superior Técnico, Lisbon, Portugal, 2011.

[15] D. Lang, C. R. Binder, B. Stäubli, K. Schleiss, and R. W. Scholz, "Optimization of waste management systems by integrating material fluxes, agents and regulatory mechanisms: the case of 
biowaste," in Proceedings of the Environment 2010: Situation and Perspectives for the European Union, Porto, Portugal, May 2003.

[16] D. Marković, D. Janošević, M. Jovanović, and V. Nikolić, "Application method for optimization in solid waste management systems in the city of Nis," Facta Universitatis-Series: Mechanical Engineering, vol. 8, no. 1, pp. 63-76, 2010.

[17] N. Husáková, "A New Approach to Eco-Logistics," Applied Mechanics and Materials, vol. 708, pp. 99-104, 2014.

[18] N. De Jaegere, M. Defraeye, and I. Van Nieuwenhuyse, The Vehicle Routing Problem: State of The Art Classification And Review, Research Center for Operations Management, Department of Decision sciences and Information Management, Faculty of Economics and Business, KU Leuven, Leuven, Belgium, 2014.

[19] I. Markov, S. Varone, and M. Bierlaire, "Vehicle routing for a complex waste collection problem," in Proceedings of the 14th Swiss Transport Research Conference, pp. 1-27, Ascona, Switzerland, 2014.

[20] E. B. E. I. Adiba, M. Elhassania, and E. H. A. Ahemd, "A hybrid ant colony system for green capacitated vehicle routing problem in sustainbale transport," Journal of Theoretical and Applied Information Technology, vol. 54, no. 2, pp. 198-208, 2013.

[21] M. Figliozzi, "Vehicle routing problem for emissions minimization," Transportation Research Record, no. 2197, pp. 1-7, 2010.

[22] H. W. Chen and N.-B. Chang, "Prediction analysis of solid waste generation based on grey fuzzy dynamic modeling," Resources, Conservation and Recycling, vol. 29, no. 1-2, pp. 1-18, 2000.

[23] E. Shamshiry, B. Nadi, and A. R. Mahmud, "Optimization of municipal solid waste management," in Proceedings of the International Conference on Biology, Environment and Chemistry, pp. 119-121, 2011.

[24] J. Kumar, D. Subbaiah, and D. Rao, "Prediction of municipal solid waste with rbf net work- a case study of eluru, A.P, India," International Journal of Innovation, Management and Technology, vol. 2, no. 3, p. 238, 2010.

[25] E. Solano, "Multi-objective Linear programming optimization for waste management simulation," in Proceedings of the Fourth International Conference on Advances in System Simulation (SIMUL'12), pp. 125-130, 2012.

[26] M. Saberi and I. Ö. Verbas, "Continuous approximation model for the vehicle routing problem for emissions minimization at the strategic level," Journal of Transportation Engineering, vol. 138, no. 11, pp. 1368-1376, 2012.

[27] I. Kücükoglu, S. Ene, A. Aksoy, and N. Öztürk, "A green capacitated vehicle routing problema with fuel consumption optimization model," International Journal of Computational Engineering Research, vol. 3, no. 7, pp. 16-23, 2013.

[28] D. L. O'Connor, Solid Waste Collection Vehicle Route Optimization for the City of Redlands, California [M.S. thesis], University of Redlands, California, Calif, USA, 2013.

[29] M. Taha, M. N. Fors, and A. A. Shoukry, "An exact solution for a class of green vehicle routing problem," in Proceedings of the 2014 International Conference on Industrial Engineering and Operations Management, pp. 1383-1390, Bali, Indonesia, January 2014.

[30] G. Ćirović, D. Pamučar, and D. Božanić, “Green logistic vehicle routing problem: routing light delivery vehicles in urban areas using a neuro-fuzzy model," Expert Systems with Applications, vol. 41, no. 9, pp. 4245-4258, 2014.

[31] E. Demir, T. Bektaş, and G. Laporte, "The bi-objective pollutionrouting problem," European Journal of Operational Research, vol. 232, no. 3, pp. 464-478, 2014.
[32] H. Han and E. Ponce Cueto, "Waste collection vehicle routing problem: literature review," Promet - Traffic and Transportation, vol. 27, no. 4, pp. 345-358, 2015.

[33] E. Jabir, V. V. Panicker, and R. Sridharan, "Modelling and analysis of a green vehicle routing problem," in Proceedings of the 12th AIMS International Conference on Management, pp. 1310-1318, Kozhikode, India, 2015.

[34] F. Rhoma, Z. Zhang, Y. Luo, and B. Noche, "Environmental \& economical optimization for municipal solid waste collection problems, a modeling and algorithmic approach case study," in Proceedings of the 12th WSEAS International Conference on Mathematical Methods, Computational Techniques and Intelligent Systems (MAMECTIS '10), pp. 205-211, Sousse, Tunisia, May 2010.

[35] A. K. Nema and S. K. Gupta, "Optimization of regional hazardous waste management systems: An improved formulation," Waste Management, vol. 19, no. 7-8, pp. 441-451, 1999.

[36] S. Alumur and B. Y. Kara, "A new model for the hazardous waste location-routing problem," Computers and Operations Research, vol. 34, no. 5, pp. 1406-1423, 2007.

[37] H. J. Quak and M. B. M. De Koster, "Delivering goods in urban areas: how to deal with urban policy restrictions and the environment," Transportation Science, vol. 43, no. 2, pp. 211-227, 2009.

[38] Y. Jiang, X. Zhang, Y. Rong, and Z. Zhang, "A multimodal location and routing model for hazardous materials transportation based on multi-commodity flow model," in Proceedings of the 9th International Conference on Traffic Transportation Studies (ICTTS '14), vol. 138, pp. 791-799, 2014.

[39] N. Touati and V. Jost, "On green routing and scheduling problem," 27 pages, 2012, https://hal.archives-ouvertes.fr/hal00674437/documen.

[40] E. Salvucci, Crecimiento Microbiano, https://esalvucci.wordpress.com/crecimiento-microbiano/, 2010.

[41] J. Jaramillo, Guía para el diseño, construcción y operación de rellenos sanitarios manuales, http://redrrss.minam.gob.pe/ material/20090128200240.pdf, 2002.

[42] L. Borzacconi, I. López, and C. Anido, "Metodología para la estimación de la producción y concentración de lixiviado de un relleno sanitario," in Proceedings of the 25th Congreso Interamericano de Ingeniería Sanitaria y Ambiental, vol. 31, pp. 1-4, Mexico, October 1996.

[43] K. Deb, Multiobjective Optimization Using Evolutionary Algorithms, New York, NY, USA, Wiley, 2001. 


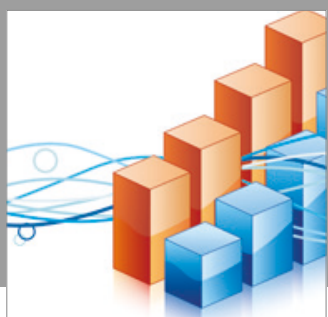

Advances in

Operations Research

vatersals

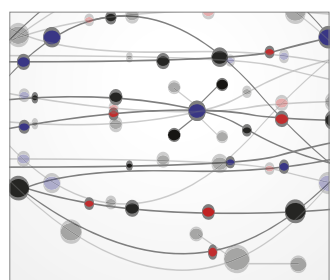

\section{The Scientific} World Journal
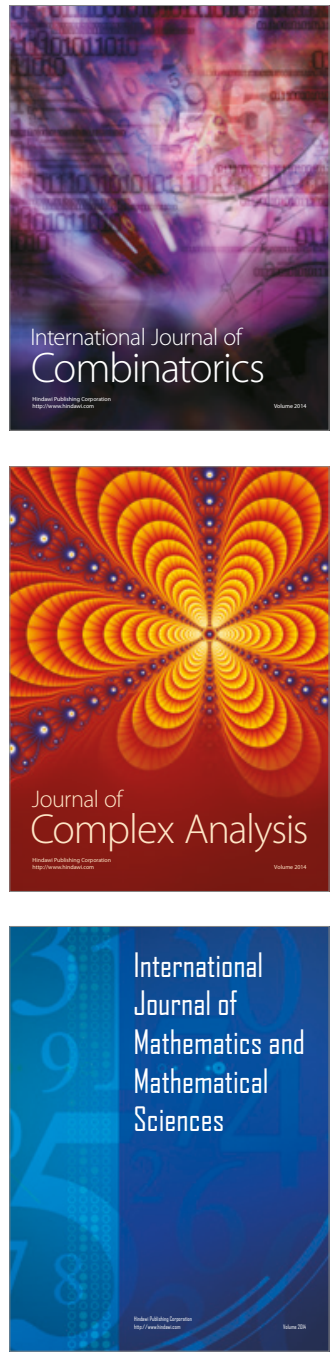
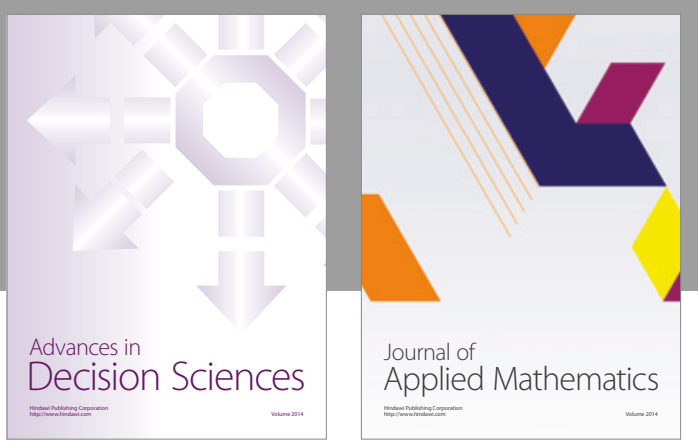

Algebra

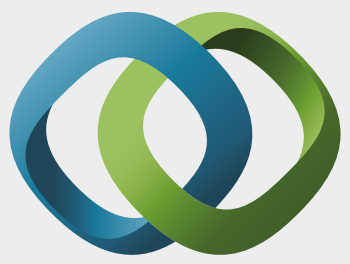

\section{Hindawi}

Submit your manuscripts at

https://www.hindawi.com
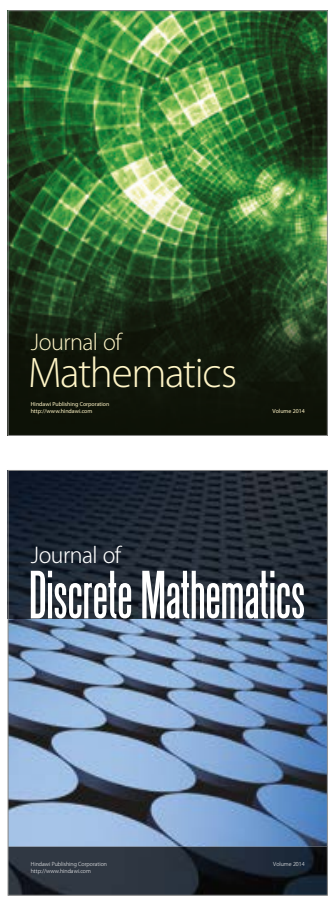

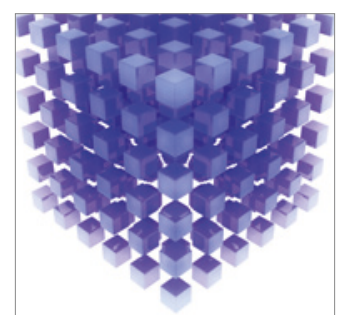

Mathematical Problems in Engineering
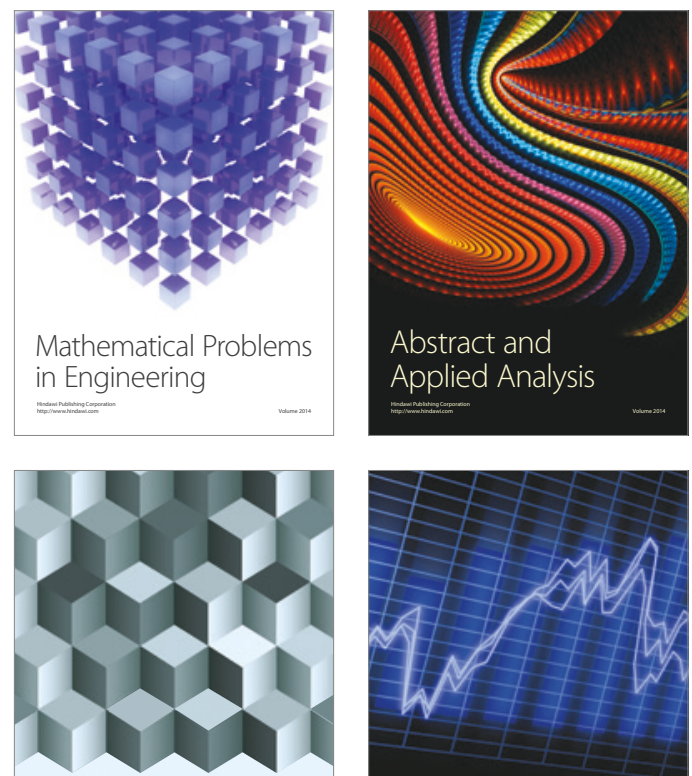

Journal of

Function Spaces

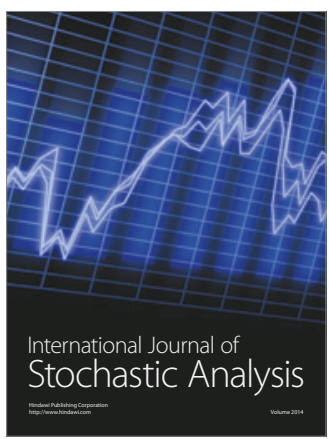

Probability and Statistics
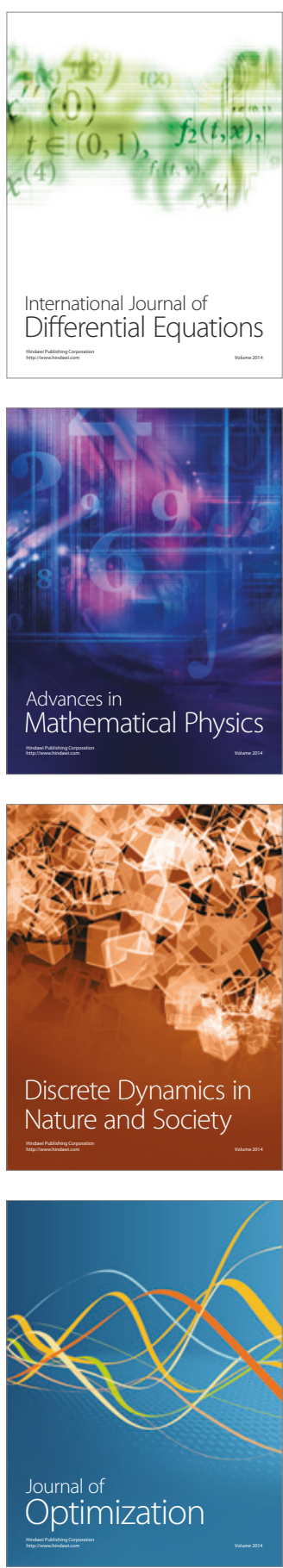